\title{
ANAESTHETIC MANAGEMENT OF BRONCHOGENIC CYST IN AN INFANT:- A CHALLENGE- A CASE REPORT
}

\section{Dr. Garima Anant*}

Dr. Aman Kaur

Saini

\section{ABSTRACT} A double-lumen tube is an endotracheal tube designed to isolate the lungs anatomically and physiologically. Double-lumen tubes are the most commonly used tubes to provide independent ventilation for each lung. One-lung ventilation or lung isolation is the mechanical and functional separation of the 2 lungs to allow selective ventilation of only one lung. The other lung that is not being ventilated passively deflates or is displaced by the surgeon to facilitate surgical exposure for non-cardiac operations in the chest such as thoracic, esophageal, aortic and spine procedures. But due to the larger size and more complex design than the single lumen tube (SLT), intubation with a DLT can be a challenge, especially in paediatric patients. We present a case of 2.5 month female child, weighing 3 kgs , diagnosed antenatally by ultrasound with bronchogenic cyst. Left thoracotomy with excision of cyst was the planned surgery for the patient

\section{KEYWORDS : Double Lumen Tubes}

\section{INTRODUCTION}

Bronchogenic cyst, a benign congenital cystic lesion of lung, is a rare cause of respiratory distress in children comprising $7.5 \%$ of all mediastinal masses. When these children are posted for surgical excision, they present a great challenge to anesthesiologists. With the use of general anesthesia, the incidence of complications in these patients has been reported to be $7 \%-18 \%$

\section{CASE REPORT}

A 2.5 month female child, weighing $3 \mathrm{kgs}$ was diagnosed antenatally by ultrasound with bronchogenic cyst, left thoracotomy with excision of cyst was planned for the patient. The Child had a history of cough and labored breathing for which symptomatic treatment was given. After 1 month, similar complaints recurred with febrile seizure. On and off febrile episodes were present since 10 days.Symptomatic treatment was given with anti-epileptic cover and patient was admitted to Pediatric Intensive Care Unit (PICU). All investigation were normal except total leukocyte count of 12000.General condition was poor. Patient was Tachypneic with chest retraction and respiratory rate was $58 / \mathrm{min}$. Heart rate was 144/min. On auscultation of chest decreased air entry on left side with bilateral wheeze and crepts were found. CVS examination was unremarkable.

After proper pre anaesthetic check up, patient was taken up for left thoracotomy with excision of cyst. Intravenous line was secured with 24-gauge cannula. . General anaesthesia was planned and patient was induced with ketamine $6 \mathrm{mg}$ and fentany $5 \mu \mathrm{g}$.After confirmation of bag and mask ventilation, suxamethonium $6 \mathrm{mg}$ was given to facilitate intubation. Successful tracheal intubation was done using cuffed endotracheal tube of internal diameter $3.5 \mathrm{~mm}$ and fixed using dynaplast after confirmation of equal and adequate bilateral air entry by auscultation of chest and capnogram.

Ventilatory settings had Low tidal volume and high respiratory rate. Maintainance was done with oxygen, sevoflurane and vecuronium. Left femoral artery and right external jugular vein were cannulated. Child was positioned in right lateral position. Cyst was embedded in left lower lobe and lobectomy was planned by the surgeons. During surgery, frequent episodes of bradycardia and desaturation were present for which surgeons were asked to stop every time but it improved immediately and spontaneously . Surgery lasted for 2 hours. At the end of surgery, neuromuscular blockade was reversed and child was extubated .Child improved and was shifted to PICU for 4 days. Child was discharged after 7 days in a stable and good condition..

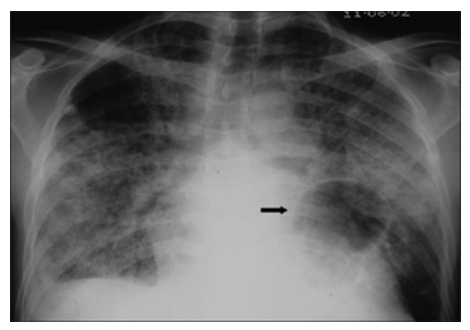

Figure 1 :- CECT chest revealed bronchogenic cyst approx. $55 \mathrm{~mm} \times 45 \mathrm{~mm}$ in the left lower lobe

\section{DISCUSSION}

In general, for thoracotomy, one lung ventilation is requested by the surgeon to facilitate surgery and prevent soiling of the dependent lung for which double lumen tube (DLT) is used . The smallest size of available conventional DLT is 26 Fr which is suitable for children above 8 years of age. The easiest means of providing one lung ventilation in pediatrics is to intubate the main stem bronchus of the non-operated lung. Standard endotracheal tubes have a low margin of safety if placed in right main stem bronchus because of the possibility of obstruction of upper lobe by the cuff of the tube. However, this can be overcome by the fiber-optic placement of tube. However, pediatric fiberscope was not available with us. Hence, we intubated the trachea and not the right main stem bronchus Other options available for pediatric one lung ventilation are single lumen endobronchial tubes, micro cuff tubes, Marraro bilumen tubes, and bronchial blockers ${ }^{1-2}$.

Chhabria et al. used microcuff endotracheal tube for lung isolation in a 5-month-old infant and 5-year-old child for thoracoscopic excision of congenital bronchogenic cyst ${ }^{3}$. The smallest size Kimberly-Clark microcuff endotracheal tube is internal diameter $3 \mathrm{~mm}$ which could be used in present case of a 2-month-old infant, but it was not available. Marraro bilumen tubes are not widely available ${ }^{4}$. It is a DLT for neonates and small children up to 2 or 3 years of age. The smallest Univent tube is $3.5 \mathrm{~mm}$ internal diameter and used for children $>6$ years of age. The smallest Arndt pediatric endobronchial blocker is $5 \mathrm{Fr}$ which may be suitable for children more than 2 years of age as it requires at least a 4.5 $\mathrm{mm}$ internal diameter endotracheal tube. This limitation can 
be managed with insertion of 5 Fr Arndt endobronchial blocker through an extraluminal technique rather than its intraluminal conventional placement ${ }^{5}$.

\section{CONCULSION}

A thorough preoperative evaluation is crucial to plan for definitive intra- and post-operative management. Constant communication with surgeons result in better outcome

\section{REFERENCES}

1. Birmingham PK, Uejima T, Luck SR. Anesthetic management of the patient with a bronchogenic cyst: A review of 24 cases. Anesth Analg 1993;76:879-83.

2. Purohit A, Bhargava S, Mangal V, parashar VK. Lung isolation, one-lung ventilation and hypoxaemia during lung isolation. Indian J Anaesth 2015;59:606-17

3. Chhabria R, Dave N, Garasia M. Thoracoscopic excision of congenital bronchogenic cyst: Use of microcuff endotracheal tube for lung isolation. J Anaesthesiol Clin Pharmacol. Doi: 10.41003/0970-9185.168259.

4. Pawar DK, Marraro GA. One lung ventilation in infants and children: Experience with Marraro double lumen tube. Paediatr Anqesth 2005; 15:204-8.

5. Bastien JL, O'Brien, Frantz FW. Extraluminal use of Arndt pediatric endobronchial blocker in an infant: A case report. Can J Anaesth 2006;53:159- 